\title{
Deep Vein Thrombosis Associated with May-Thurner Syndrome in an Amyotrophic Lateral Sclerosis Patient
}

\author{
-A Case Report-
}

Dong Kyu Kim, M.D., Jung Hoi Koo, M.D., Sun Hong Song, M.D., Ph.D., Jong Hyeog Lee, M.D. ${ }^{1}$

Departments of Rehabilitation Medicine and ${ }^{1}$ Radiology, Gangneung Asan Hospital, University of Ulsan College of Medicine, Gangneung 210-711, Korea

There have been a few reports on deep vein thrombosis (DVT) associated with compression of the left common iliac vein by the right common iliac artery, referred to as May-Thurner syndrome (MTS). However, there have been no reports on DVT associated with MTS in amyotrophic lateral sclerosis (ALS) patients exhibiting similar clinical features to paraplegic spinal cord injury patients. We hereby report a case of DVT associated with MTS in an ALS patient, who was treated successfully.

Key Words Deep vein thrombosis, May-Thurner syndrome, Amyotrophic lateral sclerosis

\section{INTRODUCTION}

May-Thurner syndrome (MTS), also known as Iliac vein compression syndrome, is caused when the left iliac vein is compressed by the right iliac artery. This syndrome was first reported by May and Thurner in 1957. ${ }^{1}$ This anatomical transformation has become a risk factor in deep vein thrombosis because the compression causes stasis of the blood.

Deep vein thrombosis (DVT) is commonly found in patients who have suffered from problems such as spinal cord injuries, old age, immobilization, quadriplegia,

Received December 21, 2009; Accepted July 9, 2010

Corresponding author: Jung Hoi Koo

Department of Rehabilitation Medicine, Gangneung Asan Hospital, University of Ulsan College of Medicine, 415, Bangdong-ri, Sacheonmyeon, Gangneung 210-711, Korea

Tel: +82-33-610-3360, Fax: +82-33-610-4960, E-mail: mdjhkoo@gnah. co.kr

Copyright $\odot 2011$ by Korean Academy of Rehabilitation Medicine obesity, oral contraceptive taking, and venous stasis. ${ }^{2,3}$ In our case, the amyotrophic lateral sclerosis (ALS) patient, accompanied by gait disturbance, suffered from deep vein thrombosis caused by stasis of venous blood.

An early diagnosis for DVT combined with MTS is often difficult and according to inappropriate treatment, it is likely that recurrence of DVT is common. Therefore, an accurate diagnosis based on medical history of the patient, as well as careful physical examination, and a choice of appropriate treatment are very important. Generally, this syndrome has been treated with an aggressive intervention treatment, such as an angioplasty or a stent insertion, because treatment with only anticoagulants is ineffective. ${ }^{4,5}$ Shin et al. ${ }^{2}$ report iliac vein compression syndrome in patients with spinal cord injuries in Korea. We have also encountered DVT caused by MTS in the left leg of an ALS patient with weakness of both lower extremities. We report on the experience and successful treatments that were performed on this patient 

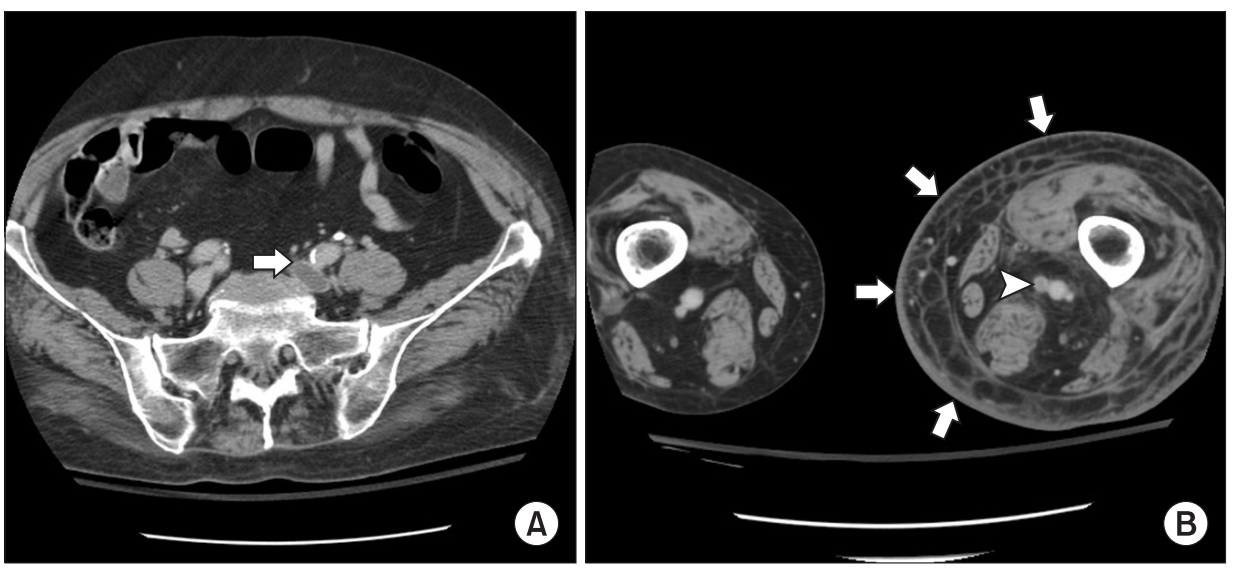

Fig. 1. CT scan showed deep vein thrombosis in left common iliac vein (A: white arrow), popliteal vein (B: white arrow head), and leg swelling (B: white arrows). forming perspective of the relevant literature.

\section{CASE REPORT}

A 71-year-old woman with a history of ALS came to our clinic because of pain and edema in the left leg, and was admitted to the department of rehabilitation medicine for evaluation and treatment.

The patient had been suffering from weakness in both her legs for 2 years. About 1 year ago the strength in her legs deteriorated, and she was diagnosed at another neurology clinic as having ALS.

Upon this diagnosis, she entered into our rehabilitation clinic for gait disturbance. Following that, she had serial follow-up and received appropriate medications. With regards to ambulation, she could walk with a walker for a short distance.

During the initial physical examination, the left leg showed a severe edema, a heating sensation, and an erythema accompanied with panthothermia. Blood tests revealed elevated white blood cell count $11.4 \times 10^{3} / \mathrm{mm}^{3}$, C-reactive protein $2.60 \mathrm{mg} / \mathrm{dl}$, D-dimer $3.87 \mathrm{mg} / \mathrm{L}$, and FDP $10 \mathrm{ug} / \mathrm{m}$.

Therefore, for the evaluation of the fracture or cellulitis, a simple radiography and a 3-phasic bone scan were performed on the patient, but there were no abnormal findings in her legs.

The pulmonary embolism computed tomography showed that the DVT in the left common iliac vein and femoral vein did not demonstrate a pulmonary thromboembolism (Fig. 1). Following this procedure, a venography was done for precise evaluation, which showed a complete obstruction in the left collateral, iliac, femoral and poplitieal vein. Thus, a thrombectomy was performed on the patient but venous flow was not recovered because there was a finding from the MTS that suggested the left iliac vein was compressed by right iliac artery. Consequently, a stent was inserted and balloon angioplasty was performed. In addition to this, Inferior Vena Cava filter was rigged (Fig. 2).

After these treatments, the left leg swelling and pain improved. There was an improved finding in the followup blood test and venography (Fig. 3). Upon receiving a comprehensive rehabilitation therapy, she was discharged with regaining her legs in their functional state.

\section{DISCUSSION}

May-Thurner syndrome is defined as the compression of the left common iliac vein by the right common iliac artery. ${ }^{2,3,6}$ In 1851, Virchow reported that the femoral iliac vein thrombosis occurs 5 more times in the left side of the body than on the right side. For almost a century, this was not well-known. Obstructive compression of the left common iliac vein by the right common iliac artery was first described by May and Thurner in $1957 .{ }^{1,7}$ Ferris $^{8}$ then coined the term for cause of chronic leg swelling as "May-Thuner syndrome".

It was found that the pulsating pressure of the right common iliac vein gave a chronic stimulus to endothelial cells in the left common iliac vein. ${ }^{5}$ This stimulus formed bumps, in the form of swelling, throughout the collagenic and thus led to an accumulation of elastin. This process ultimately leads to a hyperplasia of the endometrial blood vessel. If this structural deformation is accompanied by 

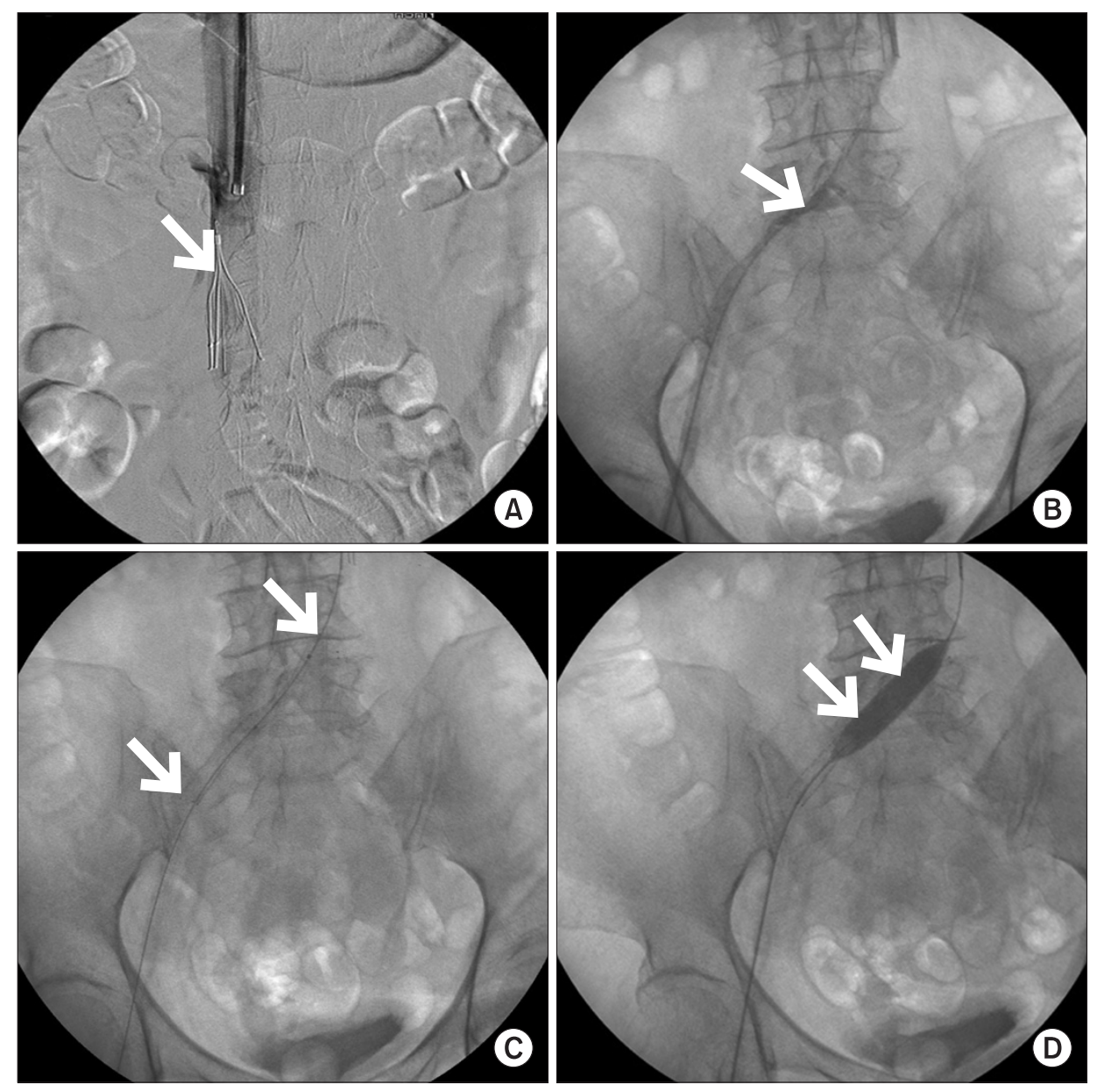

Fig. 2. Inferior vena cava filter was inserted in a supine position (A: white arrow). In a prone postion, venography showed left common iliac vein compressed by right common iliac artery (B: white arrow), suggesting MTS, and stent was inserted at stenotic portion (C: white arrows). Following that, balloon angioplasty was performed (D: white arrows).
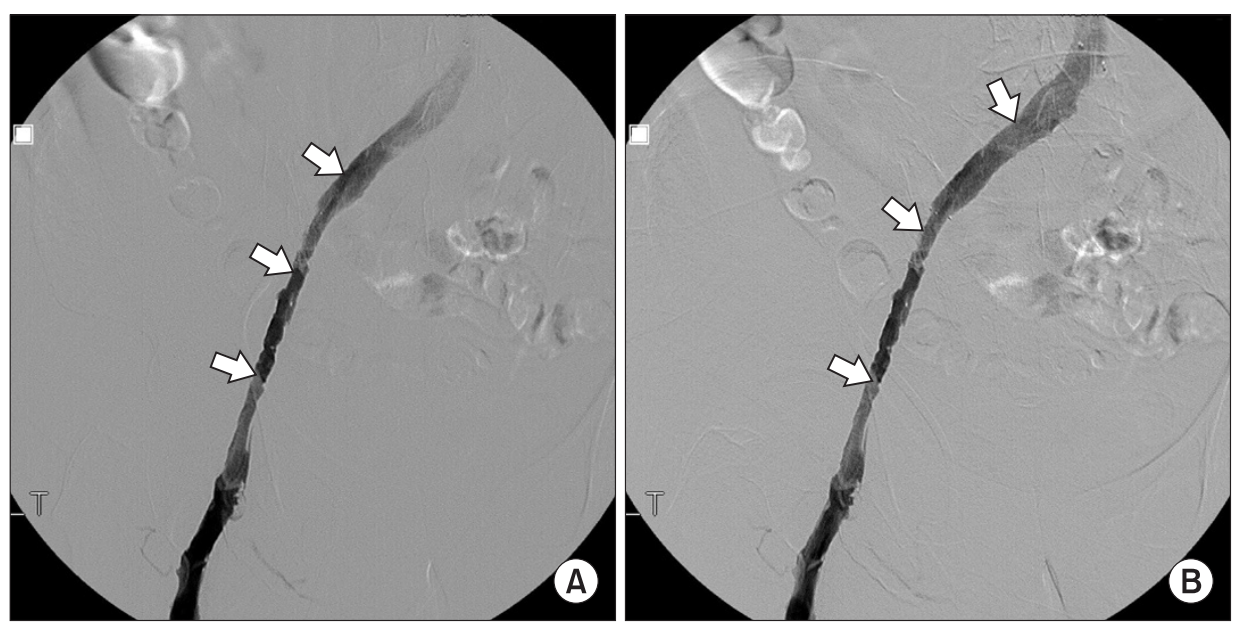

Fig. 3. Follow-up venography showed that blood flow was restored the day after intervention (A, B: white arrows).

factors such as a Virchow's triad, this can cause increased blood clotting, congestion of venous blood and damage of blood vessel inner walls owing to spinal cord injuries, operation, pregnancy, and cerebral infarction. The possibility of the outbreak of deep vein thrombosis is very high following this. ${ }^{7}$ May-Thurner syndrome can be definitively diagnosed by a venography. The existence of the collateral circulation of the vein formed by crossing pelvis is the most important information that is necessary in making an accurate diagnosis. ${ }^{9}$

Even though the side circulation in the left common iliac vein and venous flow, examining further into the inferior 
vena cava compressed by the right common iliac vein was not present in this patient, we were still confident of our diagnosis of May-Thurner syndrome, because of the deep vein thrombosis that was present in the venography of this patient.

The common remedy of deep vein thrombosis is the administration of anticoagulant after which one can prevent blood flow through the use of an elastic bandage combined with both intermittent pressure of air and passive movement of the joints in the low half of the body. Deep vein thrombosis combined with MayThurner syndrome has seen a more severe deep vein thrombosis and in many cases it threatens to relapse even after preservative anticoagulant treatment. ${ }^{10}$ According to this, catheter-directed thrombolytic therapy, balloon angioplasty and stent insertion are starting to catch on as the prevalent method since the mid-90's. A stent insertion is known to be the most effective treatment to maintain a constant long-term blood flow and to prevent relapse of deep vein thrombosis. ${ }^{1,5}$ We also treated these symptoms with angioplasty and stenting, and inserted the inferior vena cava filter to prevent the pulmonary artery embolism, which could have been created by the previous blood clot. In most cases, patients with spinal cord injury suffer from deep vein thrombosis, and because of this, studies have actively been performed since this may occur with the symptoms of iliac vein compression syndrome.

However, there are not many studies on the effects of deep vein thrombosis accompanied by May-Thurner syndrome in amyotrophic lateral sclerosis patients, even though they resemble a similar aspect in spinal injury patients, such as experience weakness in both their legs. We believe that there is a possibility of deep vein thrombosis in amyotrophic lateral sclerosis patients with serious conduct disturbances or leg weakness. Thus, the prevention and treatment of this are important especially when deep vein thrombosis of left leg occurs. When this happens, the patient should first be checked with a venography to determine whether it is accompanied with May-Thurner syndrome, since this information will ultimately help in preventing relapses and lead to successful treatment.

\section{REFERENCES}

1. May R, Thurner J. The cause of the predominantly occurrence of thrombosis of the pelvic veins. Angiology 1957; 8: 419-427

2. Shin JC, Kim EJ, Park CI, Jeon SC, Yoo JH, Lee DY. Iliac vein compression syndrome in spinal cord injury. J Korean Acad Rehab Med 2005; 29: 266-271

3. Murphy EH, Davis CM, Journeycake JM, DeMuth RP, Arko FR. Symptomatic ileofemoral DVT after onset of oral contraceptive use in women with previously undiagnosed May-Thurner syndrome. J Vasc Surg 2009; 49: 697-703

4. Acharya G, Singh K, Hansen JB, Kumar S, Maltau JM. Catheter-directed thrombolysis for the management of postpartum deep venous thrombosis. Acta Obstet Gynecol Scand 2005; 84: 155-158

5. Heniford BT, Senler SO, Olsofka JM, Carrillo EH, Bergamini TM. May-Thurner syndrome: management by endovascular surgical techniques. Ann Vasc Surg 1998; 12: 482-486

6. Chapman NH, Brighton T, Harris MF, Caplan GA, Braithwaite J, Chong BH. Venous thromboembolism management in general practice. Aust Fam Physician 2009; 38: 36-40

7. Patel NH, Stookey KR, Ketcham DB, Cragg AH. Endovascular management of acute extensive iliofemoral deep venous thrombosis caused by MayThurner syndrome. J Vasc Interv Radiol 2000; 11: 1297-1302

8. Ferris EJ, Lim WN, Smith PL, Casali R. May-Thuner syndrome. Radiology 1983; 147: 29-31

9. Baron HC, Shams J, Wayne M. Iliac vein compression syndrome: a new method of treatment. Am Surg 2000; 66: 653-655

10. Nazarian GK, Austin WR, Wegryn SA, Bjarnason H, Stackhouse DJ, Castañeda-Zúñiga WR, Hunter DW. Venous recanalization by metallic stents after failure of balloon angioplasty or surgery: four-year experience. Cadiovasc Intervent Radiol 1996; 19: 227 233164 experience. Cadiovasc Intervent Radiol 1996; 19: $227-233$ 